\title{
Modelling and Simulation of Solar-Thermal DH Systems
}

\author{
Musa O. ABDALLA \\ Mechanical Eng. Dept., The University of Jordan, Amman, 11942, Jordan \\ admin@mechatronix.us
}

\begin{abstract}
Currently, dynamical heat transfer models of the District Heating (DH) systems are needed to synthesize different types of smart building controllers. Such controllers are designed in such a way as to increase energy savings and provide highly flexible and more efficient DH systems. In this work, the complete analysis, the modelling, and the simulation of a DH thermal solar system have been investigated. A Complete mathematical modelling of the DH system components has been carried out for both the transient and steady state parts. The generated mathematical heat transfer model of the DH system has been first verified and validated through computer simulations, and it has been complemented by real collected environmental data in order to validate the derived heat transfer model. Finally, a small-scale DH system has been built and tested to validate the computer simulations, which has also been used to test a simple ON/OFF as a control strategy for the DH thermal solar system.
\end{abstract}

Keywords: District Heating, DH, Thermal solar Modelling, Heat Transfer Model, Switching Control, Transient Response.

\section{Introduction}

Presently people all over the world continue to witness the advent of a new energy crisis of our era. The energy shortage is evident by the everincreasing price of fuel. The impact on average citizens takes different forms: unbearable heating costs, an increase in food prices, hijacked gas prices, etc. The main concern of this work is to contribute to finding engineering practical solutions to lower the District Heating (DH) running costs by tapping into the solar free energy.

National and International agreements such as the Paris Agreement (French: Accord de Paris: it is an agreement within the United Nations Framework Convention on Climate Change (UNFCCC)), which deal with the greenhouse gases emissions mitigation, adaptation and finance starting in the year 2020, request countries to target and facilitate practical implementation of measures. The agreement included 195 countries, which adopted the first-ever universal, legally binding global climate deal (COP21, 2015).

Unfortunately, the energy consumption of the building sector is rising monotonically at the moment, where it constitutes more than $30 \%$ of the end energy consumption of most societies. On the other hand, the building sector is responsible for the largest amount of Greenhouse Gas Emissions (GHG) of all sectors. This is caused by their utilization of fossil fuels for the different combustion processes, which are used to satisfy the heating demands of their building stock.

District Heating (DH) strategies may significantly enhance the use of energy resources and provide better integration of renewable energies techniques into the heating sector (i.e. solar, geothermal, biomass, and industrial waste heat). Low-temperature District Heating (DH) in cold winters could be one of the vital solutions for both the generation and the demand sides (Schmidt et al., 2017) (Werner, 2017) (Abdalla et al., 2019).

Scientists and Engineers believe that the solution to the current energy crisis has to be a collection of elusive engineering actions. These measures comprise of developments in structural materials, energy control, and management, sustainable energy technology, corrective actions, etc. This work focuses on the energy control, modeling, and management for District Heating (DH) applications. For designing robust and smart controllers one needs to establish rigorous mathematical models of the dynamical thermal solar systems. Consequently, heat transfer based modeling of the DH thermal solar system is essential for the designing, verification, and validation of their synthesized controllers (Equa, 2013) (Abdalla, 2015).

District Heating research objectives may be categorized in few areas; dynamical modeling, hydraulic network design, and operation, balancing valves effects on DH systems, control and operation strategies of DH systems, and optimization of DH systems (Delmastro et al., 2016) (Mazhar et al., 2018). DH dynamical modelling is essential for simulations, control and analyzing the efficiency of district heating systems. Typically, DH has consisted of several component models such as boiler, distribution network, single or multi-zone, building enclosure, 
and terminal heaters (Xu, 2012). The engineering design and operation of the $\mathrm{DH}$ systems require the optimization of complex networks; hence simulation tools play an important role. Several commercial tools like TERMIS, sisHYD and Grades Heating have been adapted to simulate both the steady and dynamic network actions. During the last decade several of energy based modelling approaches have been proposed, verified and validated (Ben Hassine and Ursula, 2013) (Sartor et al., 2017). Some researchers considered in their model the overall DH system (i.e. globally), which consists of the production plant, pipes network and the consumers'side (Brockelman et al., 2018) (Sandou et al., 2004).

Newly developed District Heating (DH) models have been introduced by many researchers. For example, Kuosa et al, 2013 have derived a model for the $\mathrm{DH}$ under steady-state conditions. A ring distribution network topology has been utilized instead of the traditional Y-topology. It has been proposed to implement the model by using variable speed pumps (i.e. VFD technology) in contrast to valves in order to control the mass flow rates. A complete mathematical model of the system has been used to illustrate the benefits based on steady state analysis (Kuosa et al., 2013). On the other hand, some researchers have proposed a dynamically based model for a geothermal DH system. The model was verified on a University Campus and the components were modeled as macroscopic, dynamic model depending on black box approach and using heating equipment, heat loss, building energy storage and heat pump models (Gökçen et al., 2004) (Cho et al., 2017).

On the other hand, many researchers have tried to design and optimize solar thermal district heating systems (i.e. hybrid). Typically, the solar district heating $(\mathrm{DH})$ plants consist of large fields of solar thermal collectors feeding their produced solar heat into a block or DH networks in urban quarters, smaller communities, or large cities. The solar collector may be installed on the free ground or integrated into rooftops. Currently, plant capacities of $50 \mathrm{MW}$ are possible with solar thermal shares of $10-50 \%$ of the total heat supply of the DH system. The solar thermal heating applications are diverse and range from heating swimming pools to fully operational $\mathrm{DH}$ systems (Pauschinger, 2016) (Chow et al., 2012) (AlAboushi, 2017).
The demand for solar thermal heating initiated the European standard EN 15316-4-3, which is a standard method used for calculating the space heating and domestic hot water (DHW) heating for thermal / solar systems. Other dedicated tools for performing a more detailed analysis of solar heating components and systems exist in the literature (Anon, 2002). A newly developed simulation software for building energy; such as, Indoor Climate and Energy (IDA-ICE) (Equa, 2013) are also available and may be used to combine detailed building simulation models with detailed district heating substation models, which are complemented by solar heating. The IDA-ICE is a whole year detailed and dynamic multi-zone simulation application employed for studying the indoor climate of individual zones as well as the energy consumption of an entire building (Arce, 2018).

In contrast, this work provides a controller design platform for the DH solar thermal system, which includes both a transient and a steady state analysis. The integration of these parts is required by the building management systems control schemes and by the environmental comfort controller design as well. So, the present research intends to derive a complete dynamical heat transfer model of all the DH components and equipment. Unfortunately, most of the existing solar thermal DH models are based on steady state analysis, which is acceptable for design and analysis but it cannot be used to synthesize, verify and test DH controllers.

The structure and organization of this paper is the following: section two describes the research methodology used in the current study containing the dynamical modeling of the DH system, section three presents the computer simulated results and discussions that have been involved in verifying and validating the presented theory. Finally, section four highlights the main conclusions of this work.

\section{Methodology}

\subsection{Typical DH System Design}

When cooling and/or heating of two or more structures using a centralized energy source the setup is known as District Heating (DH) System. The distribution of this low temperature energy is carried out through a network (comes with different topologies) of well-insulated piping 
system (i.e. return and supply). Heat generation may be provided through different means; such as conventional boilers, solar arrays, biomass, geothermal...etc. However, fossil fuel must be an integral part of the DH system, which will be used in case of sudden needed or peak increased demand (Bloomquist, 2001). Figure 1 depicts a simplified DH thermal solar setup, which will be used in the modeling process. Basically, high efficiency conventional solar collectors will be used to heat transfer fluid, which in turn will heat the returned circulating water from the DH unit using heat exchangers. Coldwater from a storage tank is circulated through the solar collectors whenever it is feasible, and if not the circulating pump is shut off and conventional fuel is used instead. Different implementations of the same idea are possible; the design used has been preferred in terms of cost and simplicity. Typically, the operational cost savings of a well-designed DH thermal solar system, when incorporating good control strategies, exceeds 25\% (Sorensen, 2004) (Schalger \& Weisblatt, 2006) (Abdalla, 2015).

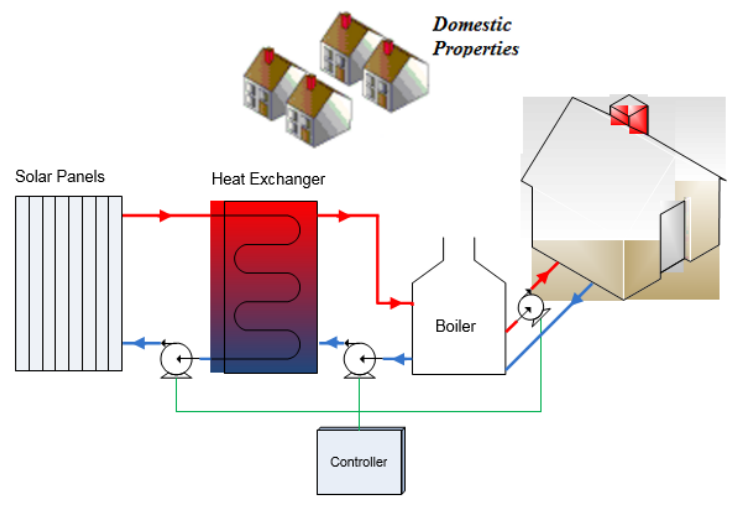

Figure 1. Standard DH System Conceptual Design

Even though the DH system is easily implemented, a lot of time is needed for modeling the heating equipment, building heat loss model, energy generation and storage components to generate a complete mathematical model for the controller design process. Developing a standard computational model, which is complemented by computer simulation, should provide a systematic design methodology and a testbed to verify and validate the diversity of designed controllers. In this work, the modeling of the piping system and its temperature drop is neglected because the pipes are assumed to be fully insulated. Besides, the variable flow rate of circulating fluids and variable return fluid temperatures are enforced (BØhm, 2010).
Finally, the DH system model consists of the heat transfer or loss model of the buildings, in-house radiators, heat exchangers, solar panels and the conventional boiler system. The integration of all the components yields the complete model of the system, which will be presented in the subsequent sections.

\subsection{Indoor Modelling}

Typically, residential houses are composed of multi-rooms equipped with radiators, which need to be modeled. Linear first order systems are used to mimic the dynamical behavior of the heat and temperature distributions in the rooms. The rooms represent the system that needs to be controlled where the temperature is the system's output (i.e. the controlled process variable).

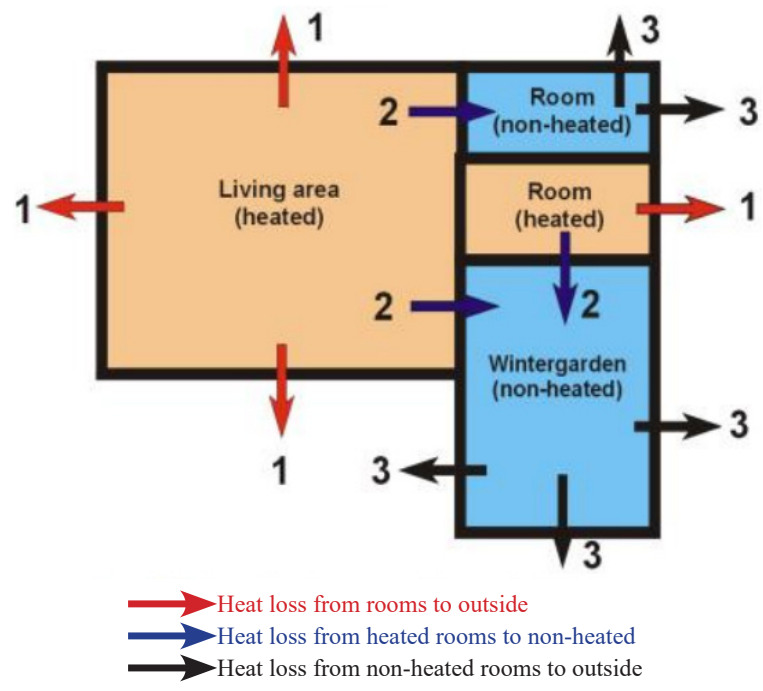

Figure 2. Energy flow for double room space

The adopted heat loss model assumes that heat may be lost through sidewalls, doors, windows, ceiling...etc., and all these factors have been combined in the value of the overall heat transfer coefficient ' $U$ '. Hence, it is easy to show that the following differential equations will govern the heat distribution in a two adjacent room system, which is fully illustrated in Figure 2. By modeling the rooms using conservation of energy laws, it will result in the following linear coupled differential equations; for example, two adjacent rooms model will look as follows:

$$
\begin{aligned}
Q_{1}= & m C_{a i r} \frac{d T_{1}}{d t}+U_{1} A_{1}\left[T_{1}(t)-T_{a}\right]+ \\
& U_{0} A_{0}\left[T_{1}(t)-T_{2}(t)\right] \\
Q_{2}= & m C_{a i r} \frac{d T_{2}}{d t}+U_{2} A_{2}\left[T_{1}(t)-T_{a}\right]+ \\
& U_{0} A_{0}\left[T_{2}(t)-T_{1}(t)\right]
\end{aligned}
$$


Where the amount of heat provided by the radiators inside the two adjacent rooms are $Q_{1}$ and $Q_{2}$, respectively, which will be stored in part by the room's indoor air and the rest will be transferred to the outside through the room's boundaries (i.e. outside and cross rooms ). One may simplify notation by using $k_{i}=U_{i} A_{i}$ and $C_{i}=m_{i} C_{p}$.

\subsection{Heating Equipment Modelling}

In the DH system design, the heat energy is transferred using heated water to the indoor or space air environment. The amount of transferred energy depends on different parameters; such as indoor temperature, water flow rates, and water supply temperatures. In this subsection, the modeling of the heating equipment is discussed, which includes the radiators, boiler and burner, and solar system. The interaction of these components with the building heat loss model that has been derived in the previous section will create the targeted simulated response of the system (Anon, 2007) (Sartor et al., 2014) (Kotulska, 2015).

1) Radiator Equipment: Radiators belong to the heat exchangers family of the $\mathrm{DH}$ heat equipment, which transfers energy from the $\mathrm{DH}$ water supply to the indoor air space. The amount of heat transferred from the DH water supply to the indoor air through radiators or heat coil units may be given as:

$Q_{i}=U_{r} A_{r}\left(T_{r}-T\right)$

In control applications, both transient and steady state analysis are needed, which makes it improper to utilize the Logarithmic Mean Temperature Difference (LMTD) to estimate the amount of heat energy transferred through the radiator. Instead one should utilize a more dynamical heat transfer model of the form:

$\dot{m}_{r} C_{p}\left(T_{b}-T_{r o}\right)-U_{r} A_{r}\left(T_{r}-T\right)=C_{r} \frac{d T_{r}}{d t}$

Where the energy supplied by the boiler (first term) is used to heat the radiator. Then it will heat the ambient air (second term) where the energy supplied by the boiler (first term) is used to heat the radiator. Finally, it will heat the ambient air (second term) as summarized by equation (4). Figure 3 depicts a small zone of the DH system, which highlights the supply and return of the water and the flow rate control using Motor Operated Valves (MOVs).

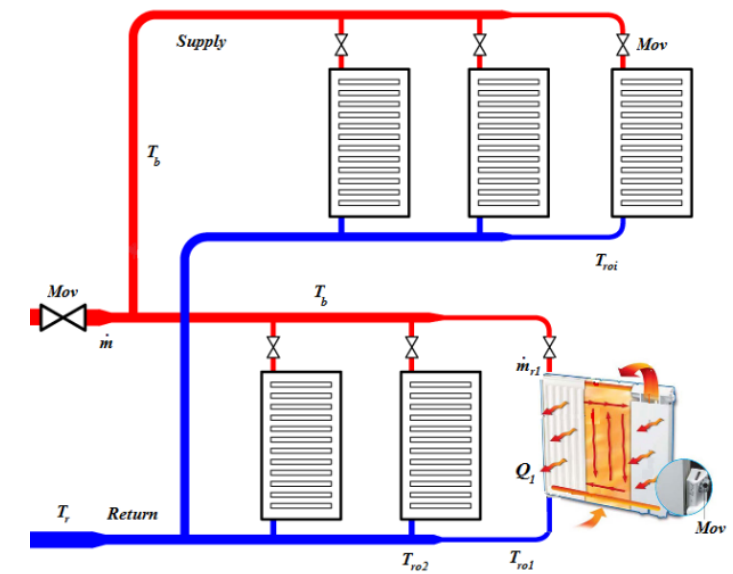

Figure 3. DH system zone radiator arrangement

2) Boiler Equipment: Taking a control volume around the boiler will result in postulating the governing equation of the boiler using energy balance. The total thermal energy within the boiler's control volume consists of three parts: a useful part that will be circulated through the $\mathrm{DH}$ system (first term), a lost part through the exhaust fumes (second term) and some parts stored within the boiler system.

$\dot{m}_{b} C p\left(T_{r}-T_{b}\right)+U_{b} A_{b}\left(T_{g}-T_{b}\right)=m_{b} C p \frac{d T_{b}}{d t}$

Initially, the boiler will utilize water with reference conditions but once the circulating system is initiated the return water temperature will be in effect. It must be kept in mind that the temperature of water streams returned from each radiator is not uniform and it is proportional to the mass flow rate set value for each radiator. Consequently, one way to find the temperature of the return line is to make a weighted sum of all the returned temperatures. Referring to Figure 3, which illustrates the different used parameters the following equation may be written to represent the return line water temperature.

$T_{(r)}=\frac{\sum T_{(r o) n} \dot{m}_{n}}{\dot{m}}$

3) Solar System: The DH supportive solar system, shown in Figure 4, it consists of circulating pumps, the array of solar collectors and an efficient Heat Exchanger (HE). There are many types of solar heat exchangers; such as shell and tube, plate, a storage tank with an integrated wraparound $\mathrm{HE}$ coil. However, the mathematical treatment is similar, which results in the following governing equations for these components: 
$U_{e x} A_{e x}\left(T_{h}-T_{m}\right)=\dot{m} C_{p}\left(T_{h}-T_{c}\right)$

$U_{e x} A_{e x}\left(T_{h}-T_{m}\right)+\dot{m}_{b} C_{p}\left(T_{r}-T_{m}\right)=C_{b-e x} \frac{d T_{m}}{d t}$

$q_{\text {solar }}+\dot{m}_{c} C_{p}\left(T_{c}-T_{h}\right)-U_{c} A_{c}\left(T_{h}-T_{a}\right)=C_{c} \frac{d T_{h}}{d t}$

Where $q_{\text {solar }}=G_{T} A_{c} \eta$ is the solar heat energy gained from the Sun.

Equation (7) represents the heat transfer model for the Heat Exchanger (HE). The first term is the heat gained by the HE and the second term is the heat transferred by the circulating water, in which the rest is stored inside the HE structure.

Please note that equation (8) represents the heat transfer within the solar collector. Some of the collected thermal energy will be transferred by the water (second term), some will be lost to ambient, and the remaining will be stored in the collector's structure.

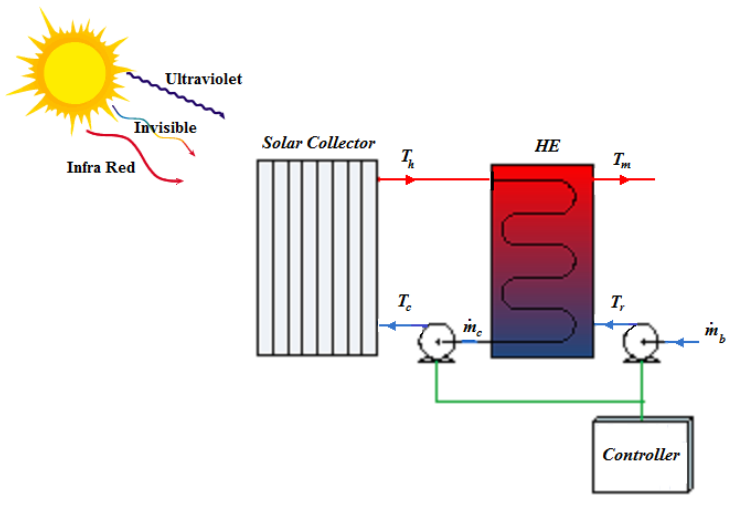

Figure 4. DH solar supportive system

4) Domestic Hot Water: The Domestic Hot Water (DHW) system is conventionally connected to utilize what is available of thermal energy. The DHW circulation has the options to be connected to the solar collector via a heat exchanger or to the boiler heat exchanger, or to an electrically energized heater or the combination of all that.

The equations that capture the thermal dynamical heat transfer model of these scenarios are as follows:

$$
\begin{aligned}
& Q_{s-D H W}=\dot{m}_{W} C_{p}\left(T_{h}-T_{c}\right)=U_{s-D H W} A_{s-D H W}\left(T_{h}-T_{D H W}\right) \\
& Q_{b-D H W}=\dot{m}_{x 13)} C_{p}\left(T_{b}-T_{r}\right)=U_{b-D H W} A_{b-D H W}\left(T_{b}-T_{D H W}\right) \\
& Q_{s-D H W}+Q_{b-D H W}+Q_{e-D H W}+\dot{m}_{D H W} C_{p}\left(T_{r e f}-T_{D H W}\right)= \\
& C_{D H W} \frac{d T_{D H W}}{d t}
\end{aligned}
$$

Equation (9) represents the DHW energy transfer complete model. Depending on the DH system valves configuration one of the first three terms will be in effect, while the fourth term represents the amount of heat transferred by the water and the rest is stored in the DHW drum or cylinder.

\section{Results and Discussion}

The District Heating (DH) dynamical thermal model will be verified using Computer simulations. A Simulink/Matlab model has been created based on the aforementioned equations (1-9) and one representative house from the DH is considered, which is depicted in Figure 5. The house consists of twelve rooms as illustrated in Figure 5. Please note that the derivation of the full house mathematical model follows the same work presented for the two room model described by equation (1-2) but it is more rigorous.

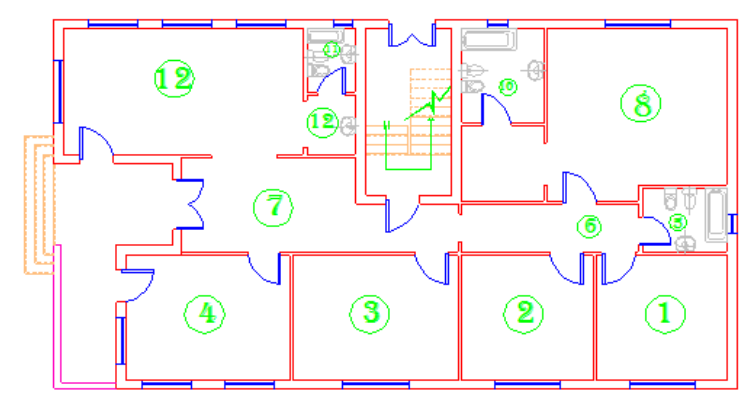

Figure 5. Full house rooms' layout plan view

Figure 6 summarizes the twelve individual rooms' temperature distribution over time, which will be referred to as "the system's response". The system's response has been generated for a step input (i.e. constant heat from all the corresponding radiators). Clearly, the system behaves as a first order system and approaches different steady state values because of the differences in heat loss through the rooms.

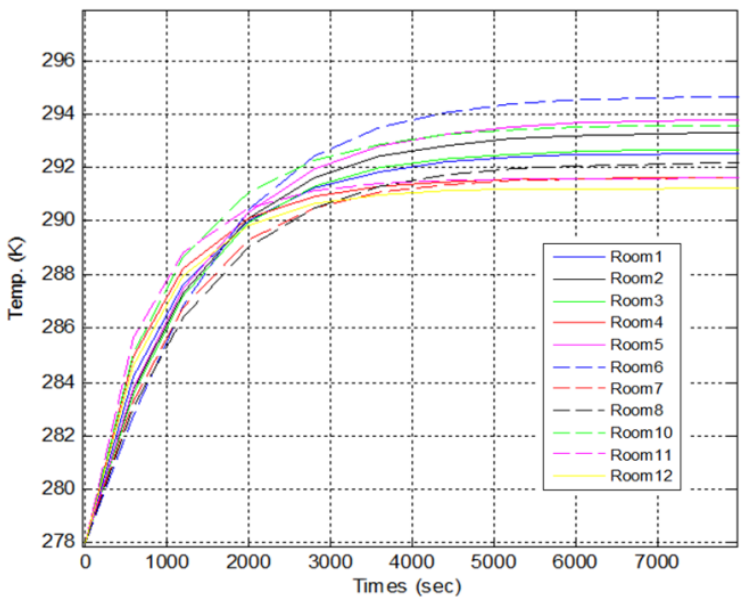

Figure 6. Open loop step system response 


\subsection{DH Control Strategies}

In the District Heating systems, multiple controllers are installed in the apartments / houses and one for the thermal solar system. The solar circulating loop and the boiler utilized for the heat exchanger loop shown in Figure 4 may be controlled by a simple On/Off controller; Figures 7 and 8 illustrate the flow chart diagram and implementation in Matlab.

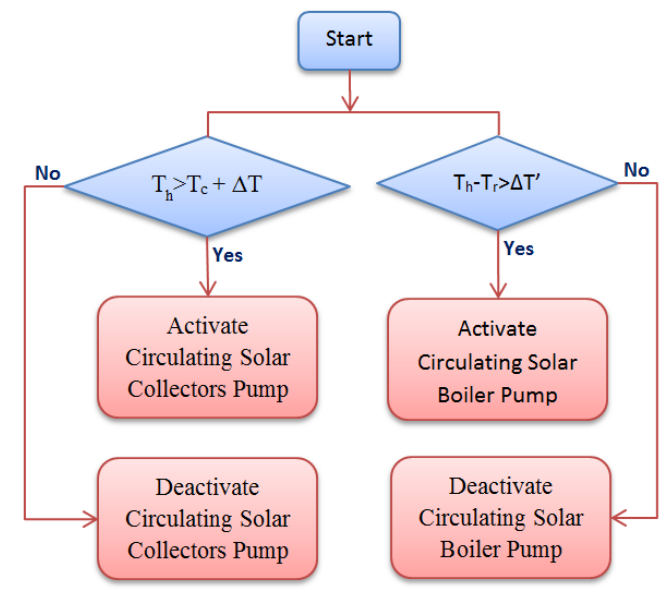

Figure 7. DH system On/Off control strategy

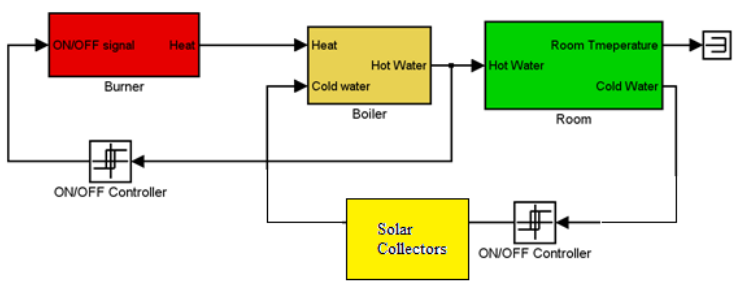

Figure 8. Matlab implementation of the On/Off

This simple adopted control strategy requires measuring the difference between certain temperatures and actuating certain devices in accordance. The On/Off control strategy has been used in conjunction with real environmental yearly data to test and verify the developed system's mathematical model and computer simulation. For example, data like irradiance, ambient temperature, and wind speed were collected from Shams Maan weather station (Anon, 2015). Finally, to reduce actuator's shattering all the implemented On/Off loops should have upper and lower bounds for proper switching (not shown in the flow chart).

Also, individual rooms may have simple On/Off controllers (i.e. thermostat) (Solis et al., 2019). Figure 9 depicts a simple On/Off controller strategy that has been simulated and implemented in this project.

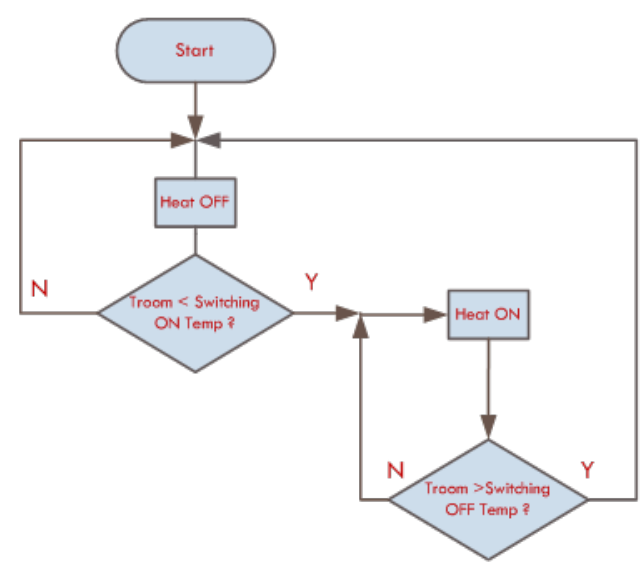

Figure 9. Individual room ON/OFF controller

\subsection{Experimental Validation}

Figure 10 depicts the experimental model response, while Figure 11 illustrates the controller actions in heating the Student Cafeteria (SC) room over a day period. Initially, when the system starts, the controller turns On the burner and the radiators' circulation pump to start heating the room (i.e. because the room's temperature is less than the controller's set point).

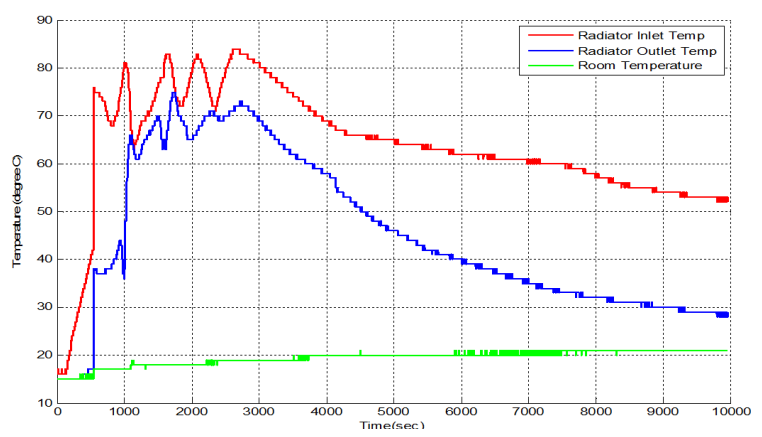

Figure 10. Experimental DH system response

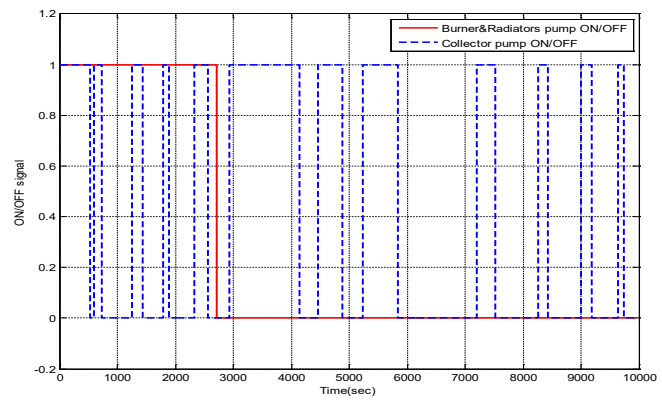

Figure 11. Controller actions or control law

The solar collector's pump is On as well; since the difference between the inlet and the outlet temperatures of the collector is greater than the switching differential. A while later the controller 
turns Off the burner and the radiators' pump but the collector's pump is still On.

A small-scale experimental model has been used to verify and validate the proposed dynamical heat transfer models of the DH system. The implementation has been accomplished in the Solar Cafeteria (SC) at the University of Jordan (JU) Campus. Figures 12-14 illustrate the actual implementation diagrams and pictures of the experimental system.

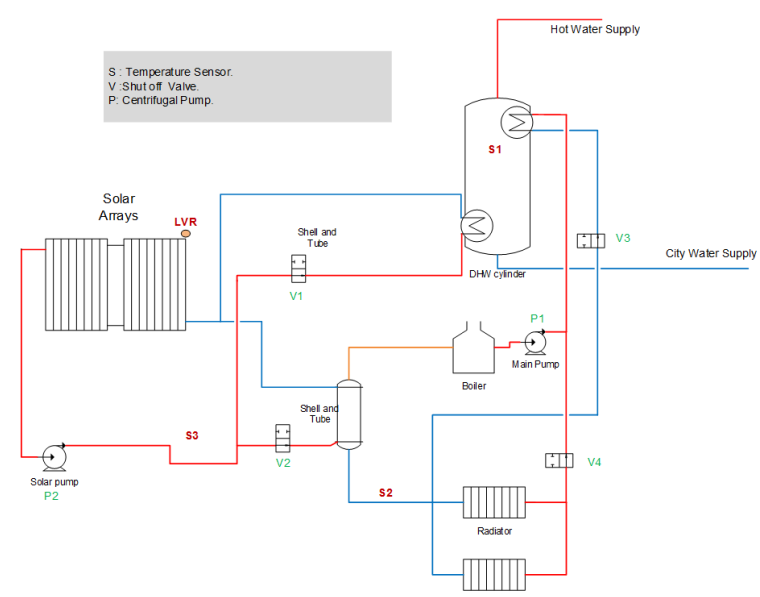

Figure 12. DH small scale system schematics

In this work, Gobi Solar Collectors have been used because of their available specific needed parameters (i.e. available from the local manufacturer), however, any type of efficient solar collectors may be used; such as vacuum tubes. Recall equations $(7,8)$ where the solar captured heat from the sun is given as (Anon, 2007).

The corresponding efficiency as supplied by the manufacturer is given as follows:

$\eta=0.7255-0.5633\left(\frac{\Delta \mathrm{T}}{\mathrm{G}}\right)-0.0022\left(\frac{\Delta \mathrm{T}^{2}}{\mathrm{G}}\right)$

Where $\Delta \mathrm{T}=\mathrm{T}_{\mathrm{c}}-\mathrm{T}_{\mathrm{a}}$.

Finaly, This experimentally designed DH system was based on the presented DH modelling techniques and simulations. The control strategy of the SC room and the controller design were also tested using the simulated model of the DH system. The SC Hybrid System with its corresponding control strategy proved to be very effective and it showed an increase of the thermal overall efficiency of about $15 \%$ producing a great impact on the system's energy savings.

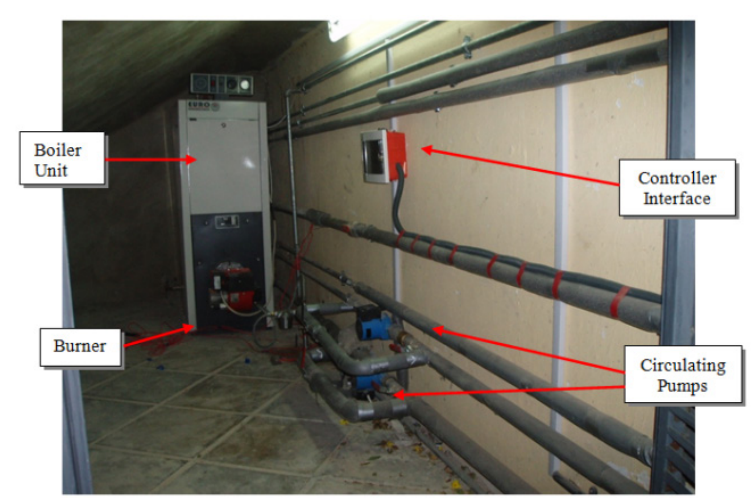

Figure 13. DH prototype system experimental setup

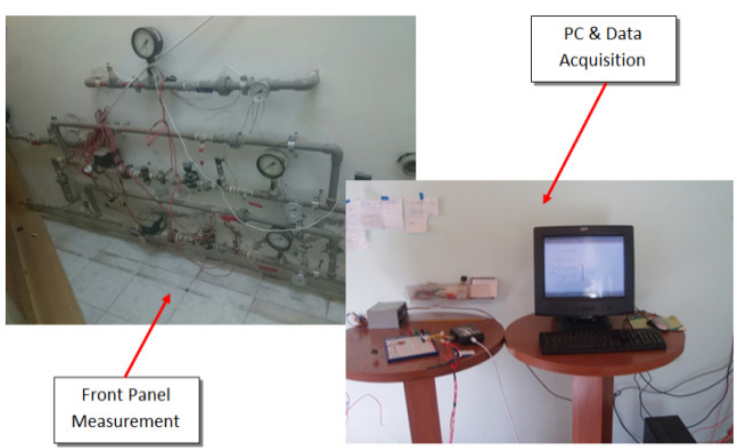

Figure 14. DH prototype measurements

\section{Conclusion}

Complete dynamical heat transfer models for the District Heating (DH) system components have been successfully derived and simulated on Simulink / Matlab $\subset$ software. The derived models have been then verified and validated using real environmental yearly collected data from a weather station in Jordan. On/Off controllers' design and implementation have been successfully performed on the simulated model.

The simulation results of the heat transfer models will generate more insights for the DH systems controller design, for both researchers and engineers. It will enable them to test the diversity of controller designs and energy management schemes. The derived DH model proved that it can serve as a robust testbed for simulating both the dynamics of transient thermal energy as well as the steady state part.

Finally, a hardware experimental setup has been usefully used to validate the derived models through the implementation of a simple On/Off controller design. However, the dynamical heat transfer model may be used to investigate several high-tech controllers design; such as Proportional, Integral, Derivative (PID) cyclic, Linear Quadratic Regulators (LQR) ...etc. 


\section{Acknowledgements}

This experimental research would not have been possible without the full support of Scientific Research Centre of The University of Jordan (JU) (1192, District Heating). Thanks are also extended to the Euro-Boiler company who was participating in FFF project and to my undergraduate students Emran, Mukhtar and Tahboob, Zaid for their help.

$\begin{array}{ll}\text { Abbreviations } \\ A & \text { Heat transfer area }\left(\mathrm{m}^{2}\right) \\ C & \text { Heat Capacity }\left(\mathrm{kJ} /{ }^{\circ} \mathrm{C}\right) \\ C_{p} & \text { Specific heat of fluid }\left(\mathrm{kJ} / \mathrm{kg}^{\circ} \mathrm{C}\right) \\ G & \text { Sun radiation }\left(\mathrm{W} / \mathrm{m}^{2}\right) \\ G_{T} & \text { Irradiance }\left(\mathrm{W} / \mathrm{m}^{2}\right) \\ m & \text { Mass of fluid }(\mathrm{kg}) \\ m & \text { Flow rate of fluid }(\mathrm{kg} / \mathrm{s}) \\ q_{\text {solar }} & \text { Collector heat gain }(\mathrm{kWh})\end{array}$

\section{REFERENCES}

Abdalla, M. (2015). Hybrid Heating System, FFF Technical Report, Industrial Outreach. The University of Jordan, Amman 11942.

Abdalla, M. \& Abuquba, H. (2019). Natural Cooling of Two Axis Tracking Photovoltaic Module, Energy Sources, Part A: Recovery, Utilization, and Environmental Effects. DOI: 10.1080/15567036.2019.1663300

Al-Aboushi, A. (2017). Solar Thermal Hybrid Heating System, Jordan Journal of Mechanical and Industrial Engineering, 3(11), 181-184.

Anon. (2002). Polysun Simulation website (Software). Available at: <http://www. velasolaris.com>.

Anon. (2007). Heating systems in buildings. Method for calculation of system energy requirements and system efficiencies, Part 4-3: Heat generation systems, thermal solar systems, EN 15316-4-3.

Anon. (2015). Maan, Shams, Jordan weather data. Amman: Shams Maan.

Arce, I., López, S., Perez, S., Rämä, M., Klobut, K. \& Febres, J. (2018). Models for fast modelling of district heating and cooling networks, Renewable and Sustainable Energy Reviews, 82, 1863-1873.

Bloomquist, R. G. (2001). Geothermal District Energy System Analysis, Design, and Development, 5th edition, Macel Rosca.

$\begin{array}{ll}Q & \text { Input heat energy }(\mathrm{kWh}) \\ T & \text { Temperature }\left({ }^{\circ} \mathrm{C}\right) \\ U & \text { Overall heat transfer coefficient }\left(\mathrm{kWm}^{2 \circ} \mathrm{C}\right) \\ \text { Greek } & \text { Letters } \\ \eta & \text { Efficiency } \\ \Delta & \text { Difference } \\ \text { Subscripts } \\ a & \text { Ambient } \\ b & \text { Boiler } \\ c & \text { Collector } \\ e & \text { Electric heater } \\ e x & \text { Heat exchanger } \\ g & \text { Hot Gas } \\ h & \text { Hot side } \\ m & \text { mass flow rate } \\ n & \text { Radiator number } \\ r & \text { Radiator } \\ r & \text { Radiator outlet } \\ (r) & \text { Return water } \\ r e f & \text { Reference (city water) } \\ s & \text { Solar } \\ D H W & \text { Domestic Hot Water cylinder }\end{array}$

Brockelman, I., Beck, S. \& Styring, P. (2018). A Simple Approach to Modeling Rural and Urban District Heating, Frontiers in Energy Research, 6(103), 1-14.

BØhm, B. (2010). Experimental Determination of Heat Losses from Buried District Heating Pipes in Normal Operation, Heat Transfer Engineering, 22(3), 41-51.

Cho, H., Smith, A., Luck, R. \& Mago, P. (2017). Transient Uncertainty Analysis in Solar Thermal System Modeling, Journal of Uncertainty Analysis and Applications, 5(1), DOI: 10.1186/ s40467-017-0055-6

Chow, T., Tiwari, G. \& Menezo, C. (2012). Hybrid Solar - a Review on Photovoltaic and Thermal Power Integration, International Journal of Photoenergy, 17p. Article ID307287. DOI: $10.1155 / 2012 / 307287$

Delmastro, C., Mutani, G. \& Schranz, L. (2016). The evaluation of buildings energy consumption and the optimization of district heating networks: a GIS-based model, International Journal of Energy and Environmental Engineering, 3(7), 343-351.

Equa. (2013). IDA Indoor Climate and Energy, User Manual. Equa Simulation AB.

General Report. (2015). Climate Conference. In COP21 Paris, France. 
Hassine, I. B. \& Ursula, E. (2013). Impact of load structure variation and solar thermal energy integration on an existing district heating network, Applied Thermal Engineering, 50, 1437-1446.

Kotulska, K. A. (2015). Simplified space-heating distribution using radiators in Norwegian passive houses: Investigations using detailed dynamic simulations. Thesis, Norwegian University of Science and Technology, Department of Energy and Process Engineering.

Kuosa, M., Kontu, K., Mäkilä, T. \& Lampinen, M. (2013). Static study of traditional and ring networks and the use of mass flow control in district heating applications, Applied Thermal Engineering, 54(1), 450-459.

Mazhar, A., Liu, S. \& Shukla, A. (2018). A state of art review on the district heating system, Renewable and Sustainable Energy Reviews, 96, 420-439.

Pauschinger, T. (2016). Solar thermal energy for district heating. Science Direct, Advanced District Heating and Cooling (DHC) Systems, 99-120.

Sandou, G., Stéphane, F. \& Sihem, T. (2004). Global modelling and simulation of a district heating network. In Proceedings of the $9^{\text {th }}$ International Symposium on District Heating and Cooling, Espoo, Finland (pp. 117-140).

Sartor, K., Lemort, V. \& Dewallef, P. (2017). Improved district heating network operation by the integration of high temperature heat pumps, International Journal of Sustainable Energy, 37(9), 842-856.
Sartor, K., Quoilin, S. \& Dewallef, P. (2014). Simulation and optimization of a CHP biomass plant and district heating network, Applied Energy, 130, 474-483.

Schlager, N. \& Weisblatt, J. (2006). Alternative Energy. Detroit: Thomson Gale.

Schmidt, D., Kallert, A., Blesl, M., Svendsen, S., Nord, N. \& Sipilä, K. (2017). Low Temperature District Heating For Future Energy Systems. In The $14^{\text {th }}$ International Symposium on District Heating and Cooling, Stockholm: Svensk Fjarrvarme (pp. 8-15).

Solis, M. A., Olivares, M. \& Allende, H. (2019). A Switched Control Strategy for Swing-Up and State Regulation for the Rotary Inverted Pendulum, Studies in Informatics and Control, 28(1), 45-54. DOI: 10.24846/v28i1y201905

Sorensen, B. (2004). Renewable Energy. Elsevier Science, Denemark.

Werner, S. (2017). International review of district heating and cooling, Energy, 137, 617-631.

Xu, K. (2012). Thermal and Hydraulic Modelling and Control of a District Heating System. Thesis in Applied Science at Concordia University Montreal, Quebec, Canada.

Yıldırım, N. \& Gökçen, G. (2004). Modeling of Low Temperature Geothermal District Heating Systems, International Journal of Green Energy, 1(3), 365-379. 